\section{Case Reports in Orthopedic Research}

Ol: $10.1159 / 000505531$

Published online: January 23, 2020
(C) 2020 The Author(s)

Published by S. Karger AG, Basel www.karger.com/cio

This article is licensed under the Creative Commons Attribution-NonCommercial 4.0 International License (CC BY-NC) (http://www.karger.com/Services/OpenAccessLicense). Usage and distribution for commercial purposes requires written permission.

\title{
Severe Cervical Spinal Kyphosis: Technical Case Reports on the Way of Microsurgical Management
}

\author{
Forhad H. Chowdhury ${ }^{a} \quad$ Mohammod Raziul Haque ${ }^{b}$ \\ aNational Institute of Neurosciences and Hospital, Dhaka, Bangladesh; \\ bDepartment of Neurosurgery, Dhaka Medical College Hospital, Dhaka, Bangladesh
}

\section{Keywords}

Severe kyphosis - Cervical spine · Posterior approach · Posterior partial corpectomy . Translateral mass and transforaminal approach

\begin{abstract}
A young man presented with quadriparesis due to severe kyphosis of the cervical spine. In the first posterior operation, the spinal cord was decompressed by laminectomies and posterior partial corpectomy through bilateral translateral mass and transforaminal approach followed by posterior stabilization and fusion. In the second operation, the cervical spine was stabilized and fused through an anterior approach. The patient recovered completely from his neurological deficit with very minimal neck movements. We report this case to describe the bilateral translateral mass and transforaminal partial posterior cervical corpectomy for spinal cord decompression followed by posterior and anterior stabilization and fusion.
\end{abstract}

(C) 2020 The Author(s)

Published by S. Karger AG, Basel

\section{Introduction}

During the past decades, there has been a growing interest and advancement in the management of complex cervical spine disorders such as severe cervical kyphosis. Improved 
understanding of the biomechanics involved in both normal and pathological conditions of the cervical spine [1, 2], as well as application of innovative spinal instrumentation [3-5], have enlightened the way for an aggressive and successful surgical approach to these disorders. Here, we report a successful surgical management of a complex and severe cervical spinal kyphosis with quadriparesis in new surgical techniques.

\section{Case Report}

A 26-year-old day laborer presented with neck pain and progressive weakness in all four limbs for the last year. The weakness progressed severely in the last month. In the last month, he was unable to stand and walk. In this period, he was unable to take care of himself. He was of below-average build. His neck movements were severely restricted. His chin was almost touching the manubrium sterni and no space was found even with effort for forceful extension of neck. Inspection and palpation over the cervical spine showed severe kyphotic deformity. His higher psychic function and cranial nerves were normally functioning. Muscle power was MRC grade 2/5 in the upper limb and nonfunctioning muscle power with spasticity in the lower limbs. Hoffman sign was bilaterally positive and planter response was extensor bilaterally. All deep tendon jerks were exaggerated. All sensory modalities were reduced up to $60 \%$ below C4 level bilaterally. His autonomic functions seemed to be normal except for urge incontinence. He had no features suggesting skeletal dysplasia. He had no history of trauma, infection, or operation. Plain X-ray lateral view showed severe kyphosis of the cervical spine involving C4, C5, and C6. MRI showed severe kyphosis with spinal cord compression at C4, C5, and C6, mostly at C5 level (Fig. 1a). CT scan of the cervical spine showed kyphosis with most posterior displacement of $\mathrm{C} 5$ body along with severe canal stenosis at this level (Fig. 1b-d). After extensive clinical and radiological evaluation, we decided to operate on him in two stages; first through a posterior approach and then an anterior approach. Patient party was counseled properly.

\section{First Operation}

Under general anesthesia with endotracheal intubation (fiber-optic endotracheal intubation facilities were made available during intubation, though it was not needed), the patient was positioned in prone with $15^{\circ}$ head up. The neck was kept in neutral position. The head and cervical spine were put on Gardner-Well's tong traction. Through midline incision and careful paraspinal muscle dissection, spinous process, laminae, facet joints, and lateral masses were exposed bilaterally from C1 to C7, which were severely misaligned and grossly varied in size, shape, and orientation. Then, C5 spinous process, lateral masses, and facets were identified. C3 to C6 laminectomies were done very carefully under microscope with a high-speed drill. Spinous processes and lamina were preserved for fusion purpose. The bones were extraordinarily hard to drill. C5 lateral masses were removed completely and the upper part of C6 and the lower part of C4 lateral masses were removed partially (small part) with the drill. Both vertebral arteries were freed from vertebral canal and safeguarded. During arterial mobilization, troublesome venous bleeding was encountered, which was managed carefully by bipolar diathermy and surgical packing with hemostatic agents. C5 and C6 nerve roots were identified and safeguarded with radicular vessels. C5 vertebral body was reached and confirmed by $\mathrm{C}$-arm radiology. The posterior part of $\mathrm{C} 5$ body was drilled (with cutting and diamond burr) very carefully and patiently from the right and left side behind the spinal cord by keeping in mind the position and respect of the spinal cord, nerve roots, and vertebral arteries. 
During drilling, microscopic vision was made comfortable by depressing skin, fascia, and paraspinal muscles and elevation and rotation of operation table. Extra time was allocated for drilling. Drilling was stopped when the posterior surface of body of $\mathrm{C} 5$ was flush with the posterior surfaces of the lower and upper part of body of C4 and C6, respectively. Once again, the bone was extraordinarily hard to drill. Posterior stabilization was made bilaterally by lateral mass screws and rod fixation. Due to varied size, shape, and orientation of the lateral masses, screw placement was uncomfortable and difficult. Screws could be comfortably given in C1, $\mathrm{C} 2, \mathrm{C} 6$, and C7 on the left side and C2, C3, C6, and C7 on the right side. Directions of screws were to adjust according to shape and orientation of lateral masses (Fig. 2). Then, bilateral posterior-lateral fusion was made by autologous bone chips and also by heterologous bone chips. After that, hemostasis wound was closed in layers without drain. The operation took seven hours and three units of blood transfusion.

The patient recovered well from general anesthesia. He began to improve his neurological status in the limbs very rapidly from the first postoperative day (POD). He was able to stand with support on the 10th POD and he could walk with support on the 14th POD. He was allowed to walk independently for a limited distance on the 23rd POD with a hard neck collar. On the 28th POD, his second operation was conducted.

\section{Second Operation}

Under general anesthesia with endotracheal intubation, the patient was operated in supine position having $10^{\circ}$ head elevation. The chin of the patient was under traction with micropore as an effort for keeping the chin away from the manubrium. Even with surface traction, very minimal space was created between the chin and manubrium. A right-sided oblique incision was made along the lower two-thirds of anterior border of sternocleidomastoid. Then, anterior surface of vertebral column was reached by careful dissection between carotid sheath and tracheolarynogo-esophago-pharyngeal plane. Middle thyroid vein was coagulated and cut. Inferior thyroid artery was identified and cut after coagulation with the safeguard of recurrent laryngeal nerve. Even with the effort of extensive dissection, very minimal space was found to reach the vertebral column. Longus coli muscles and fascia were dissected to clear the anterior surface of kyphosed cervical spine. Self-retaining retractor was placed to expose the anterior surface of cervical spine. Then, anterior surface of spine was decorticated by high-speed drill under microscopic magnification. The deepest anterior surface of C5 was exposed with extreme difficulty. Heterologous bone chips were placed on the kyphosed decorticated anterior surface of spine and the deeper part was filled with chips. An anterior plate was placed and fixed by screws in C3 and C7 bodies with much difficulties; C3 screws were to put through the lower part of C2 body and C2-C3 intervertebral disc (Fig. 3 and Fig. 4). Then, the wound was closed with a drain.

The patient recovered well from anesthesia. From the 4th day of the second operation, the patient was allowed to walk with a hard collar. The collar was kept for next 3 months. The patient was well and active in his Italian tea stall (he changed his occupation) 1.5 years after the second operation. Though he was repeatedly counselled for postoperative stiff and immobile neck, but during the follow up he complained several times for neck stiffness.

\section{Discussion}

The common causes of development of complex cervical spinal disorder are trauma, postlaminectomy kyphosis, multilevel spondylosis, rheumatoid arthritis, infection, congenital 
anomaly, Larsen syndrome, skeletal dysplasias, osteogenesis imperfecta, OPLL, etc. [2, 6, 7]. In our case, we found no direct cause for development of such severe complex cervical kyphosis. As per operatively we found various developmental anomalies, i.e., hypo- and hyperplasia of laminae, facets and lateral masses with malorientation of joints are the predisposing factors behind the development of severe kyphosis.

The aims of surgery in our case were:

- Safe decompression for neuro-recovery,

- Stable (may be almost motionless) cervical spine,

- Some reduction without injuring vertebral artery, nerves, roots, and cord (no need of beautifully reduced cervical spine in post-op X-ray).

In this case, due to severe kyphosis, the space between the chin and manubrium sterni was very poor even with forceful extension of the neck. But here, severe and most important compression on the spinal cord was from the front. So we planned two stages operation; first a posterior approach and later an anterior approach. Through the posterior approach, laminectomies allowed posterior decompression of the spinal cord and more importantly, it allowed spaces and safety to the cord during the further steps of the operation. We removed the posterior-inferior part of $\mathrm{C} 5$ body, which was the most compressing element through the posterolateral approach after removal of lateral mass with safeguard of vertebral arteries and nerves bilaterally after having pulsatile spinal cord. During the posterior operation, we achieved some correction of kyphosis. Stable cervical spine, decompressed and functioning spinal cord, and increased space between chin and sternum made the second operation a little less difficult.

The main focus of the treatment of cervical kyphosis correction is to relieve pain, improve alignment of the neck, and improve or prevent neurological deficit. Deciding factors in the planning of management include the presence of spinal cord compression, the flexibility of the deformity, previous surgery, the location of the deformity, and the presence of preexisting anterior or posterior fusion $[8,9]$. If the cord compression is anterior, then it usually requires anterior decompression $[8,10]$. Flexibility of deformity is an important factor for planning of surgery. If the deformity is fixed, fusion of facet joints should be evaluated. If the desired extension is achieved, deformity correction can be performed using a posterior approach $[8,11]$. If the desired extension cannot be achieved, extra release along with posterior instrumentation may be required. Flexible deformities usually require realignment surgery, whereas more complex, fixed deformities require surgical correction using a combined (anterior plus posterior) approach or osteotomies. The location of the deformity is also an important factor. Focal kyphosis of the cervical spine can be treated by anterior corpectomy and fusion [8, 9]. Anterior, posterior, and combined approach with circumferential or pedicular subtraction osteotomies can be used for surgical treatment of cervical kyphosis. In fixed severe kyphosis, there is micro-instability, so combined anterior and posterior fusion and fixation should be done. White and Panjabi [12] stated the idea that corpectomy in patients with post-laminectomy kyphosis further destabilizes the spine. It is recommended to add the posterior instrumented fusion in patients undergoing anterior corpectomy and fusion for post-laminectomy kyphosis [8].

Controversy continues to surround the most effective method for decompression, reconstruction, and stabilization of complex cervical spine disorders. Although it is becoming increasingly clear that anterior plating for single-level corpectomies enhances arthrodesis and diminishes graft extrusion $[2,3,13]$, the effectiveness of anterior plating in decreasing graft dislodgment or promoting fusion in multilevel corpectomies is less clear [14]. Posterior decompressive approaches without placement of instrumentation are indicated in patients with multi-segmental stenosis (for example, congenital or degenerative disease) with preserved 
lordosis $[2,15]$. Although many authors have reported satisfactory results by using either the anterior and posterior approach alone, graft dislodgment, plate failure, pseudoarthrosis, progressive kyphotic deformities, and halo vest-related complications remain significant concerns [2].

In the presence of a kyphotic deformity requiring multilevel vertebrectomies, anterior reconstruction with plates and simple (non-halo) bracing may not be the optimum treatment. When confronted with this clinical picture, a combined anterior-posterior approach may yield a very high fusion rate with few graft- or plate-related complications. In the literature, however, there are few reports of experience with a single-stage combined anterior-posterior approach $[16,17]$.

The literature regarding the management of these more complex cervical spinal disorders is far from conclusive. Various methods of reconstruction have been proposed, including anterior, posterior, and combined approaches, using a variety of internal fixation devices and postoperative orthoses $[3,13-15,17]$. Idiopathic, fixed, and severe cervical kyphosis is very rare. So its appropriate management is yet to be determined.

\section{Conclusions}

The posterior operation for anterior and posterior decompression of the spinal cord by laminectomies and partial posterior corpectomy as well as posterior stabilization and fusion followed by anterior stabilization and fusion represents a viable option in the treatment of a selective group of patients with complex severe cervical kyphosis for better neurological outcome.

\section{Statement of Ethics}

Consent for publication was taken from the patient's party.

\section{Disclosure Statement}

There are no competing interests.

\section{Author Contributions}

All author were involved in data collection, reviewing, interpretation, and manuscript preparation and its edition. 


\section{Case Reports in Orthopedic Research}

\section{References}

1 Maiman DJ, Yoganandan N. Biomechanics of cervical spine trauma. Clin Neurosurg. 1991;37:543-70.

2 Schultz KD Jr, Mclaughlin MR, Haid RW Jr, Comey CH, Rodts GE Jr, Alexander J. Single-stage anteriorposterior decompression and stabilization for complex cervical spine disorders. J Neurosurg. 2000 0ct;93(2 Suppl):214-21.

3 Johnston FG, Crockard HA. One-stage internal fixation and anterior fusion in complex cervical spinal disorders. J Neurosurg. 1995 Feb;82(2):234-8.

4 Kostuik JP, Connolly PJ, Esses SI, Suh P. Anterior cervical plate fixation with the titanium hollow screw plate system. Spine. 1993 Aug;18(10):1273-8.

5 Swank ML, Sutterlin CE 3rd, Bossons CR, Dials BE. Rigid internal fixation with lateral mass plates in multilevel anterior and posterior reconstruction of the cervical spine. Spine. 1997 Feb;22(3):274-82.

6 Daivajna S, Jones A, Hossein Mehdian SM. Surgical management of severe cervical kyphosis with myelopathy in osteogenesis imperfecta: a case report. Spine. 2005 Apr;30(7):E191-4.

7 Mohindra S, Savardekar A. Management of upper cervical kyphosis in an adolescent with Larsen's syndrome. Neurol India. 2012 Mar-Apr;60(2):262-4.

8 Gadia A, Shah K, Nene A. Cervical Kyphosis. Asian Spine J. 2019 Feb;13(1):163-72.

9 Tan LA, Riew KD, Traynelis VC. Cervical spine deformity-part 2: management algorithm and anterior techniques. Neurosurgery. 2017 Oct;81(4):561-7.

10 Riew KD, Kuklo T. Cervical decompression. In: DeWald R, editor. Spinal deformities: the comprehensive text. New York (NY): Thieme Medical Publishers; 2003. pp. 517-27.

11 Herman JM, Sonntag VK. Cervical corpectomy and plate fixation for postlaminectomy kyphosis. J Neurosurg. 1994 Jun;80(6):963-70.

12 White AA 3rd, Panjabi MM. Biomechanical considerations in the surgical management of cervical spondylotic myelopathy. Spine. 1988 Jul;13(7):856-60.

13 Seifert V, Zimmermann M, Stolke D, Wiedemayer H. Spondylectomy, microsurgical decompression and osteosynthesis in the treatment of complex disorders of the cervical spine. Acta Neurochir (Wien). 1993;124(2-4):104-13.

14 Macdonald RL, Fehlings MG, Tator CH, Lozano A, Fleming JR, Gentili F, et al. Multilevel anterior cervical corpectomy and fibular allograft fusion for cervical myelopathy. J Neurosurg. 1997 Jun;86(6):990-7.

15 Epstein N. The surgical management of ossification of the posterior longitudinal ligament in 51 patients. J Spinal Disord. 1993 Oct;6(5):432-54.

16 McAfee PC, Bohlman HH, Ducker TB, Zeidman SM, Goldstein JA. One-stage anterior cervical decompression and posterior stabilization. A study of one hundred patients with a minimum of two years of follow-up. J Bone Joint Surg Am. 1995 Dec;77(12):1791-800.

17 Hirabayashi K, Bohlman HH. Multilevel cervical spondylosis. Laminoplasty versus anterior decompression. Spine. 1995 Aug;20(15):1732-4. 


\section{Case Reports in Orthopedic Research}

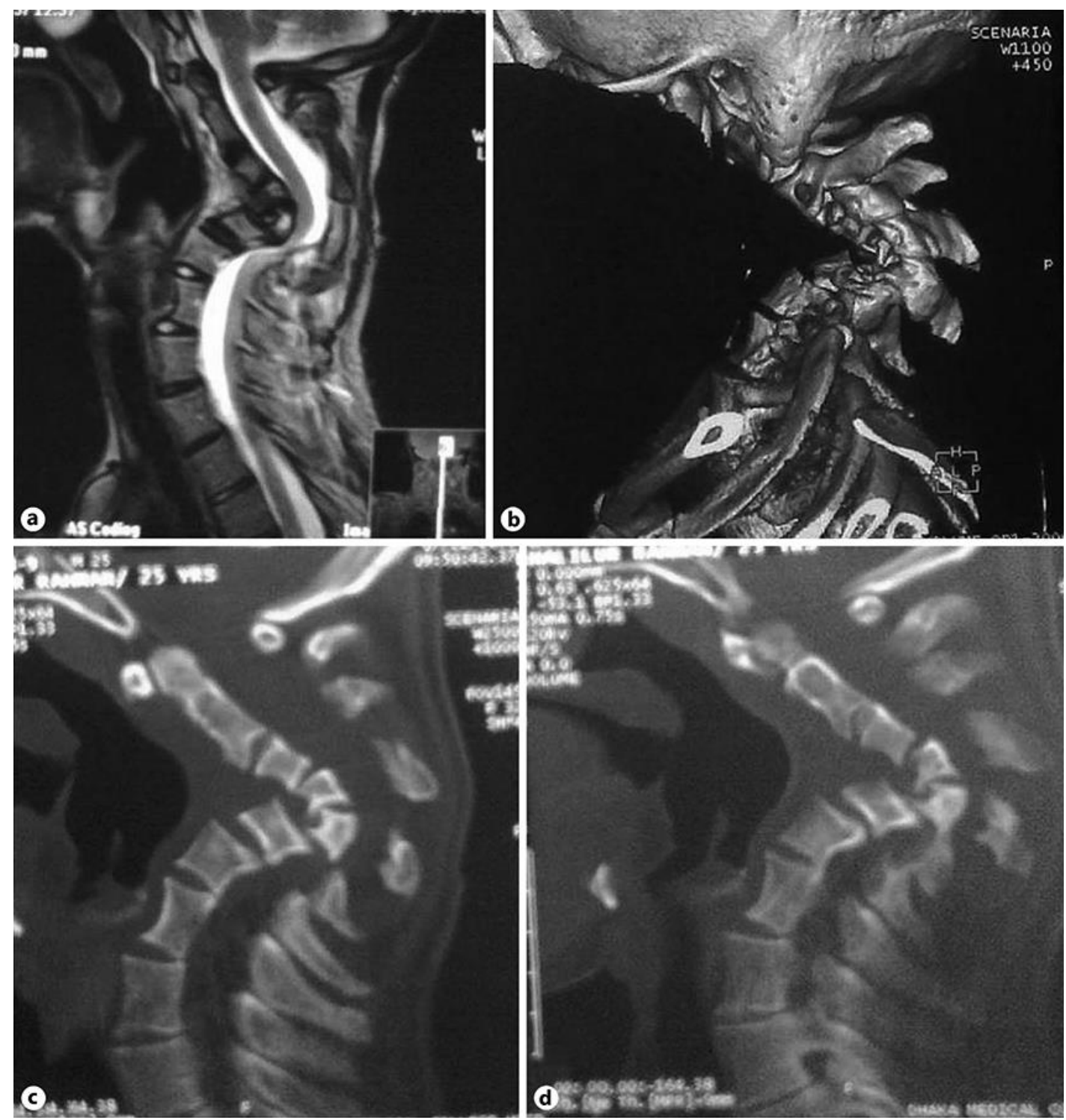

Fig. 1. a MRI of cervical spine sagittal T2W image showing severe cervical spinal deformity (kyphosis) with spinal cord compression at C5 and C6 level. b CT scan of cervical spine 3-D image. c, d CT scan of cervical spine sagittal images showing severe and complex cervical spinal kyphosis. 


\section{Case Reports in Orthopedic Research}

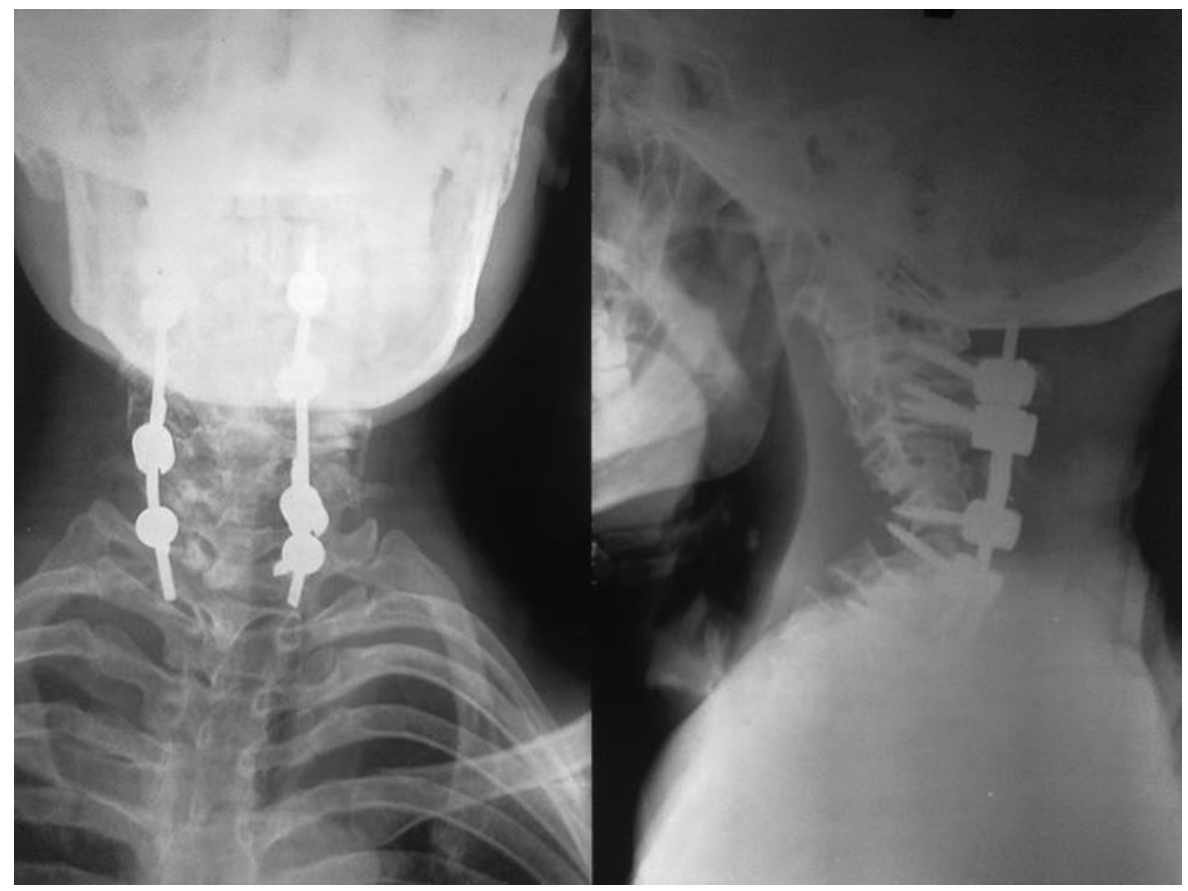

Fig. 2. X-ray cervical spine A/P view (left) and lateral view (right) after the first operation showing partially corrected cervical kyphosis with posterior stabilization by lateral mass screws and rods.

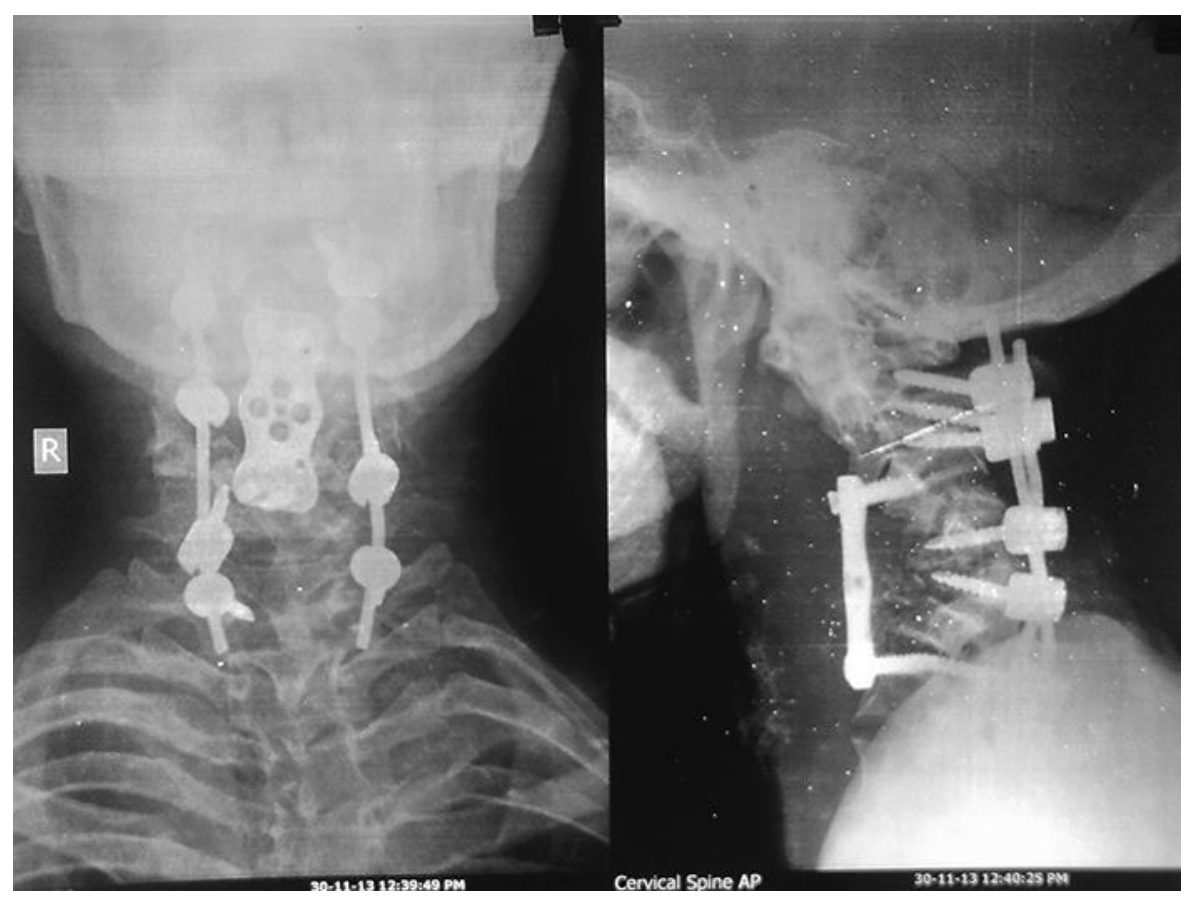

Fig. 3. X-ray cervical spine A/P view (left) and lateral view (right) after the second operation showing partially corrected cervical kyphosis with posterior stabilization by lateral mass screws and rods as well as anterior stabilization by plate and screws. 


\section{Case Reports in Orthopedic Research}

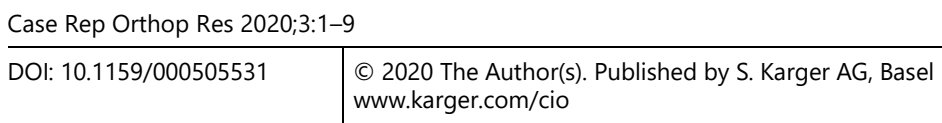

Chowdhury and Haque: Severe Cervical Spinal Kyphosis: Technical Case Reports on the Way of Microsurgical Management
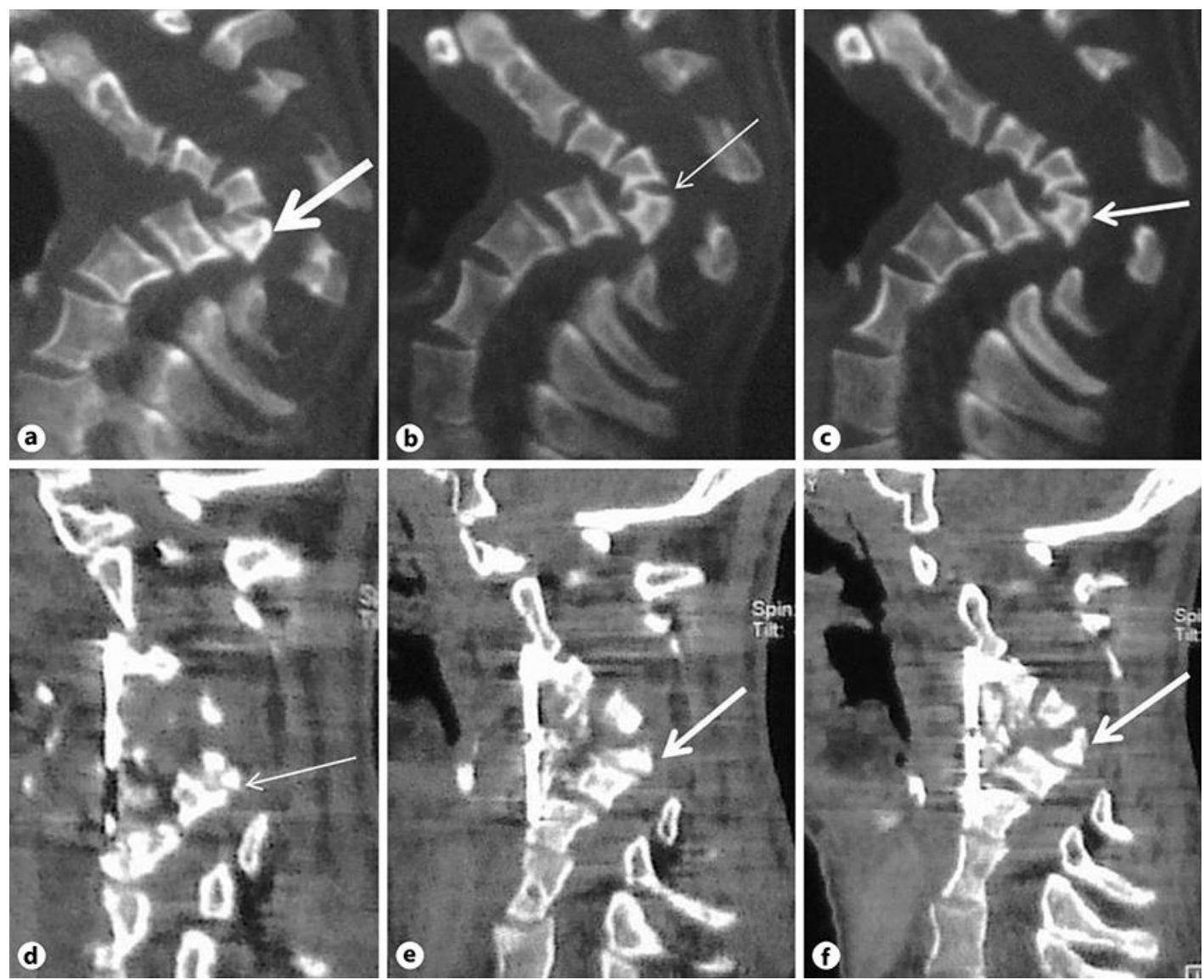

Fig. 4. a-c Preoperative CT scan of cervical spine in sagittal images showing kyphosis with most posteriorly displaced body of C5 (arrow). $\mathbf{d}-\mathbf{f}$ Postoperative CT scan of cervical spine in sagittal images showing partial correction of kyphosis, laminectomies, resection of posterior part of C5 (arrow), anterior plate, and fusion. 